\title{
Standards for Birthweight at Gestation Periods from 32 㝘 to 42 weeks, Allowing for Maternal Height and Weight
}

\author{
J. M. TANNER and A. M. THOMSON \\ From the Department of Growth and Development, Institute of Child Health, University of London, and MRC $\overrightarrow{\vec{\omega}}$ \\ Reproduction and Growth Unit, Newcastle upon Tyne

\begin{abstract}
Tanner, J. M., and Thomson, A. M. (1970). Archives of Disease in Childhood,
\end{abstract} \\ 45, 566. Standards for birthweight at gestation periods from 32 to 42 weeks, \\ allowing for maternal height and weight. Standard charts are given for assessing \\ the normality of birthweight for length of gestation from 32 to 42 weeks; first-born \\ and later-born infants are shown separately, and allowance is made for maternal height \\ and mid-pregnancy weight.
}

One of the consequences of the present interest in perinatal biology is a demand for standards of intrauterine growth as reliable and useful as the standards for postnatal height and weight. Since the early papers of Lubchenco et al. (1963) several authors have endeavoured to provide well-based and practical standards. None of these attempts, however, can altogether escape criticism, and none to date takes into account the size of the mother, a factor of considerable importance.

The data on the course and outcome of pregnancies among the women of Aberdeen during the years 1948 to 1964 are perhaps unique in their completeness. They include height and mid-pregnancy weight of the mother, birthweight, and as reliable estimates of length of gestation as can be achieved. There was no secular trend in birthweight from 1948 to 1964 , and nearly the whole population of Aberdeen is represented. These data were reported in detail by Thomson, Billewicz, and Hytten (1968), and all the present paper does is to give charts for practical use based upon them.

Boys and girls are considered separately (Fig. 1 and 2), since at least from 35 weeks on they clearly differ in birthweight. First-born and later-born children are also considered separately, by having two systems of centiles on each chart. The standards for first-born are given by the dotted median and shaded areas labelled in sloping capitals; the standards for later-born by the series of lines marked with upright capitals. The data were smoothed in the original report and no further graduation was necessary in drawing the charts.

Received 27 February 1970.
Age is in completed weeks: thus the line at $34+\vec{Z}$ represents all babies with lengths of gestation from

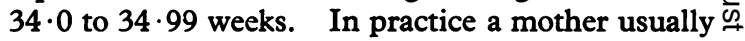
can only give the gestation to the last completed $\overrightarrow{0}$ week, so that usually the birthweight will be looked $O$ up on the lines marked $34+, 35+$, and so on.

The smaller graphs above the centile charts represent the adjustment for maternal height and mid-pregnancy weight. They are taken from Table XII in the original paper (with a misprint $\frac{\circ}{\circ}$ corrected). Their presentation in graphic form $\cong$ makes their use a little easier and permits rapid $\overrightarrow{\overrightarrow{0}}$ interpolation. Enter the mother's height and weight 3 at mid-pregnancy (interpolated by eye) and find how much above or below the zero line the newborn weight adjustment lies. It is not necessary to read it; simply use a piece of paper, a transparent rule, or, best, a pair of dividers to transfer this distance to the $\frac{3}{3}$ chart below. Add or subtract this distance from the birthweight of the child in question and plot this adjusted birthweight, at the given gestation length; read off the centile position. If maternal height but not weight is known, use the large dots on the upper graphs.

The adjustment is probably a little hazardous at $N$ the earliest ages, but can be made with confidence from 37 weeks on. The full force of the adjustment is not quite given by these graphs, since the centiles $\omega$ have not been narrowed from the population distribution to the residual distribution about the regression of birthweight on maternal size, as in $\Phi$ the postnatal standards of Tanner, Goldstein, and Whitehouse (1970). Since the multiple correlation coefficient of maternal height and weight with newborn weight is only about 0.25 the narrowing 


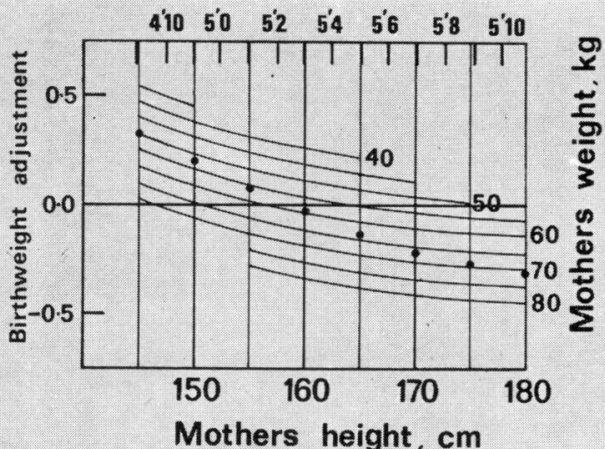

Adjustment for mother's height and mid-pregnancy weight to be add or subtracted from birthweight. Scale as in chart below. If weightunknown, use - points.

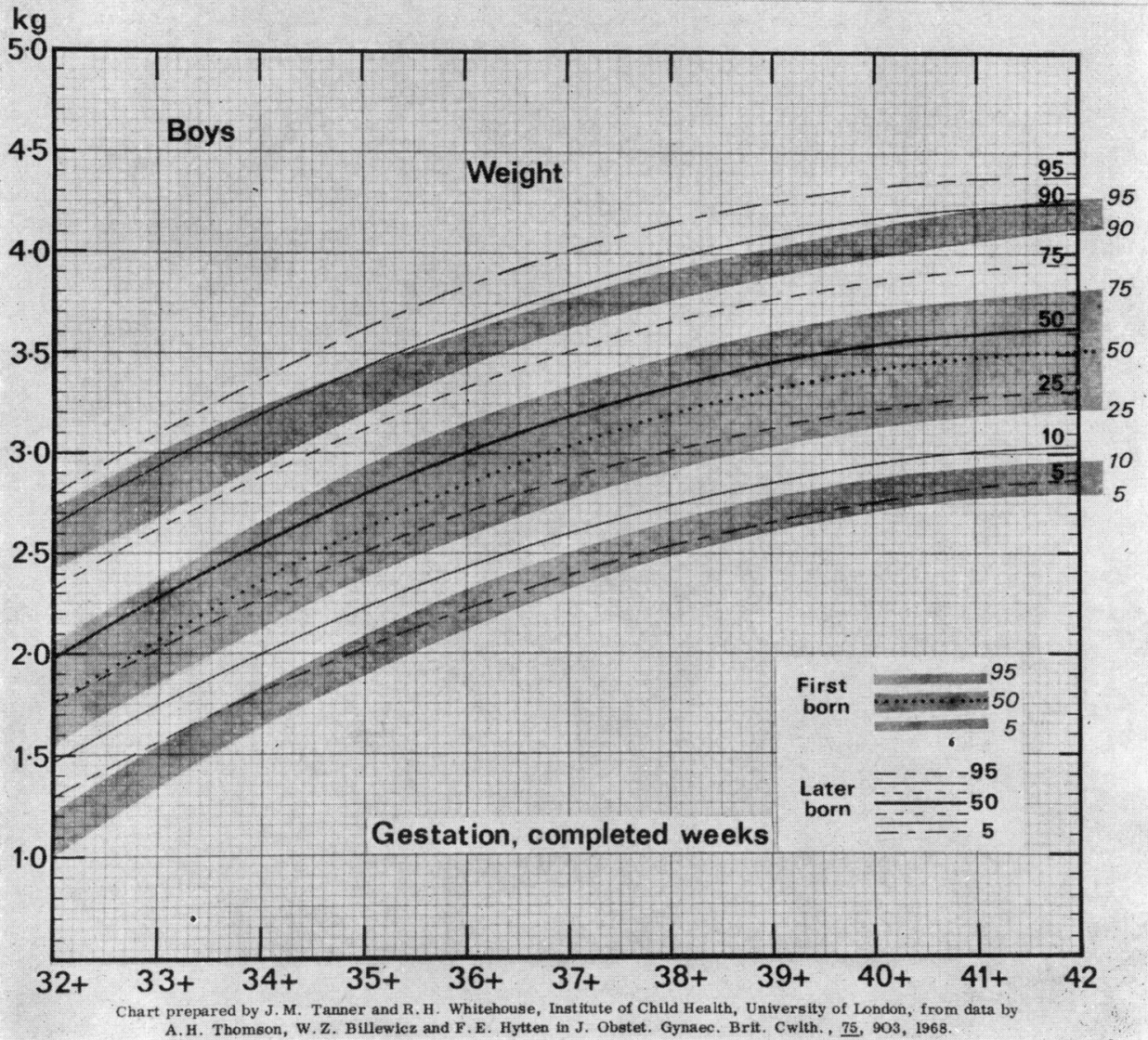

Frg. 1.-Weight chart for newborn boys, based on data of Thomson et al. (1968). The centiles for first-born are given by the dotted median and shaded bands as indicated, labelled in italic figures; those for later-born by the system of lines labelled in upright figures. Gestation is in completed weeks; thus the child born at '34 weeks' is looked up on the vertical line rising from the point marked $34+$. 


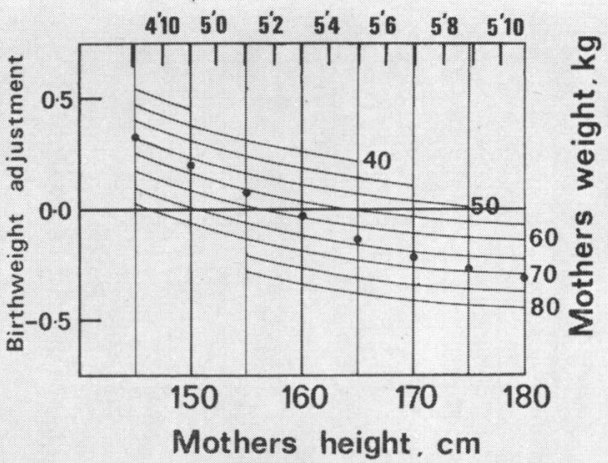

Adjustment for mother's height and mid-pregnancy weight to be added or subtracted from birthweight. Scale as in chart below. If weight unknown, use - points

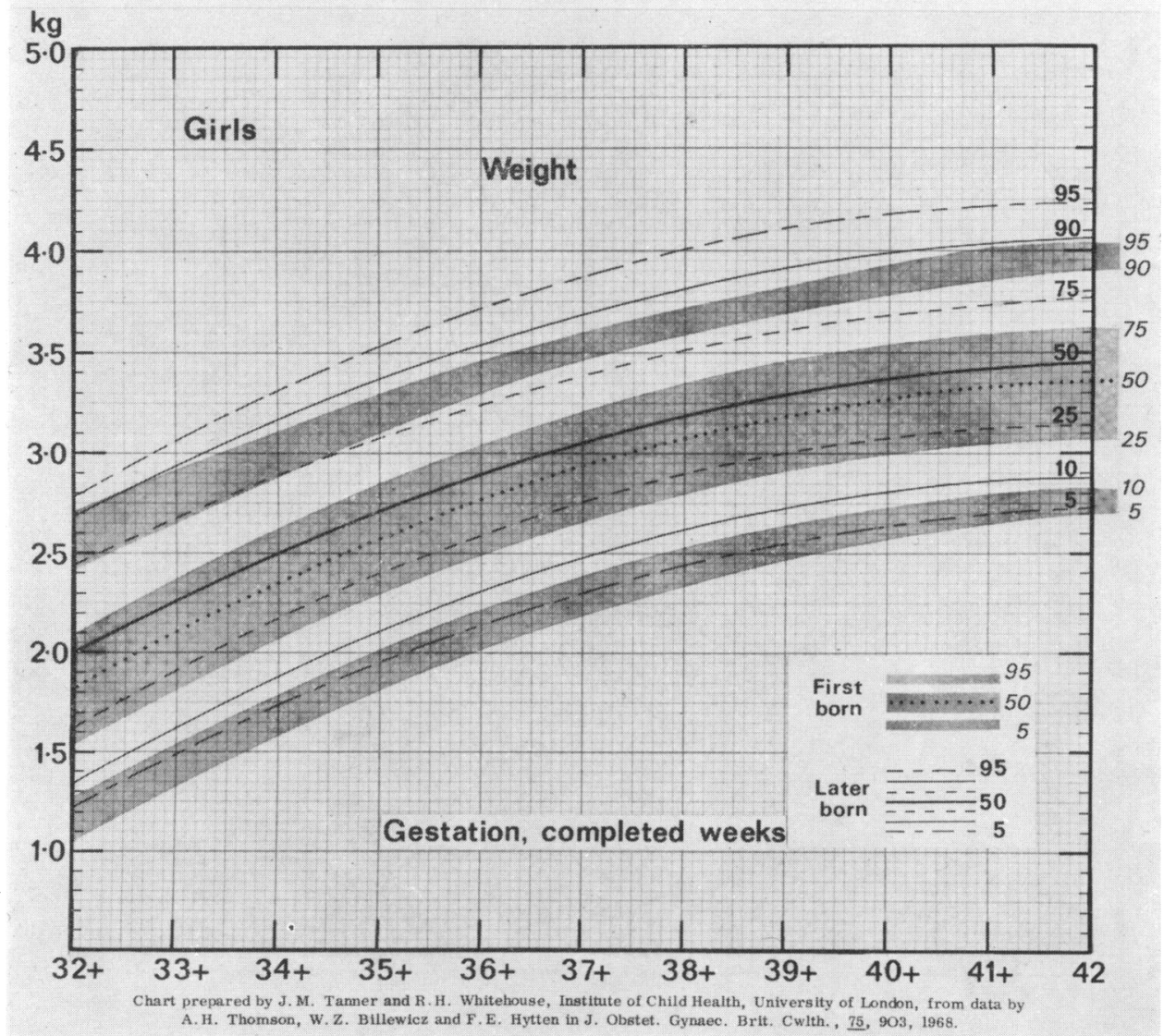

FIG. 2.-Weight chart for girls. The centiles for first-born are given by the dotted median and shaded bands as indicated, labelled in italic figures; those for later-born by the system of lines labelled in upright figures. Gestation is in completed weeks; thus the child born at ' 34 weeks' is looked up on the vertical line rising from the point marked $34+$. 
of the centiles would be less than in the postnatal situation.

It is perhaps worth noting that these Aberdeen babies are among the largest reported. The Swedish newborns of Sterky (1970) are larger, but the all-Britain 1958 Perinatal Mortality Survey values are somewhat lower (Butler and Alberman, 1969), as are the American Emory University values given by Freeman (1970). Gruenwald's (1967) American values are considerably lower, and Lubchenco's values lower still. The difference between the Swedes and the Aberdonians is probably related to maternal size rather than to socio-economic status or antenatal care. Assuming the average Swedish mother is $5 \mathrm{~cm}$. taller than the Aberdonian, and that the regression of birthweight on maternal size holds between, as well as within, both studies, one would expect a median birthweight difference of $120 \mathrm{~g}$., and this closely approximates the figure actually found.

These charts are recommended as the most suitable standards available at present for newborns in the United Kingdom.
We wish to thank Drs. W. Z. Billewicz and F. E. Hytten for their work in preparing the original data, and Mr. R. H. Whitehouse for drawing the charts.

\section{REFERENCES}

Butler, N. R., and Alberman, E. D. (1969). Perinatal Problems: The Second Report of the 1958 British Perinatal Mortality Survey. Livingstone, London and Edinburgh.

Freeman, M. G. (1970). Pediatrics (in the press).

Gruenwald, P. (1967). Growth of the human foetus. In Advances in Reproductive Physiology. Vol. II, p. 279. Ed. by A. McLaren. Logos Press, London.

Lubchenco, L. O., Hansman, C., Dressler, M., and Boyd, E. (1963) Intrauterine growth as estimated from liveborn birth-weight data at 24 to 42 weeks of gestation. Pediatrics, 32, 793.

Sterky, G. (1970). Pediatrics (in the press).

Tanner, J. M., Goldstein, H., and Whitehouse, R. H. (1970). Standards for height of British children age 2 to 9, allowing for parental height. Archives of Disease in Childhood (in the press). Thomson, A. M., Billewicz, W. Z., and Hytten, F. E. (1968). The assessment of fetal growth. fournal of Obstetrics and Gynaecology of the British Commonwealth, 75, 903.

Correspondence to Professor J. M. Tanner, Department of Growth and Development, 30 Guilford Street, London W.C.1. 